\title{
Capstone Design in Engineering and Society at McMaster University
}

\author{
C.J. Churchill ${ }^{1}$ and B.W. Baetz ${ }^{2}$ \\ ${ }^{1}$ Assistant Professor, Department of Civil Engineering, McMaster University \\ ${ }^{2}$ Professor, Department of Civil Engineering, McMaster University \\ (church@mcmaster.ca)
}

\begin{abstract}
Engineering and Society is a five-year program at McMaster University which is available to all departments within the Faculty of Engineering. A new core course, offered for the first time in the Winter 2009 semester, was taken by Society students in their final year. This course is a capstone design course titled "Design for Society". The course culminated in a group design project wherein the students were given an open-ended problem and were asked to provide a conceptual solution. The problem involved the territorial government of Nunavut, Canada, wanting to give a boost to its tourist trade while showcasing the culture, history and heritage of their people. This case study paper provides an overview of the challenges and successes of delivering this course and will be of interest to those individuals who are contemplating the development and launch of a multidisciplinary engineering design course offering.
\end{abstract}

\section{Introduction}

The Engineering \& Society program was founded in 1991 at McMaster University and was formed to explore the human side of engineering. Engineering and Society is a five-year program open to students in all of the departments in the Faculty of Engineering. Through core courses that deal with culture, history and sustainability, the program develops broadly educated, resourceful engineers with a multidisciplinary outlook, strong communication skills, and an awareness and appreciation for their responsibility to, and affect on, society. In the Engineering and Society program, a set of focused electives and a series of required core courses are taken in addition to the basic 4-year engineering curriculum. This allows engineering students who have a strong interest in another subject (such as music, geography, or history, for example) to take focus electives in that subject as well. Students are required to take eighteen units in their focus electives, which amounts to six courses. If students carefully plan their program of study they can graduate with a minor in another subject through their focus electives.

An integral part of the Society experience is inquiry-based learning. Three mandatory inquiry courses develop skills and expertise in question-driven research. Inquiry can promote student learning through guided and, increasingly, independent investigation of complex questions, problems, and issues, often for which there is no single answer. Rather than teaching through the use of fixed lectures, where students learn passively, instructors assist students in becoming proficient in self-directed learning through the process of active investigation. According to Lee [5] the inquiry process promotes a number of skills including:

- The ability to formulate good questions.

- Identify and collect appropriate evidence.

- Analyze and interpret results.

- Formulate conclusions.

- Evaluate the worth and importance of those conclusions.

The Engineering and Society program fits in very well with the current thinking on engineering education. In 1999 the Canadian Academy of Engineering published an article that recommended that "Engineering faculties should emphasize the development of the learning skills of their students" [6]. A growing body of literature supports the notion that priority should be given to move students towards "learning how to learn" [6] and that these skills will prepare students for their careers. According to a survey reported by Goel [2], a majority of responding students and faculty members felt that:

- Creativity is very important for the engineering profession.

- Current engineering education, in general, does not enhance creativity.

- Design assignments, real-life like assignments and discussions play a very important role, while written exams do not contribute significantly in fostering creativity. 
Schank and Cleary [8] state that conventional teaching methods involving only lectures, and problem sets, neither promote creativity nor do they develop the independent thought processes sought by employers. Standard courses for engineering and technology students generally aim to impart a fixed amount of established knowledge, concepts, and skills, and do not emphasize exploration, imagination, and creativity. Furthermore, research has indicated that repeated learning experience in this traditionally delivered format makes many creative and discoveryoriented students disinterested and uninspired, moulding them to be dependant and passive learners [3].

The Engineering and Society program is innovative and embraces non-standard teaching methods but its curriculum remained relatively unchanged since its inception in 1991. The following sections describe a new capstone design course and list the successes and challenges that were encountered during its first offering.

\section{Capstone Course 2.1 Background}

As with every program of study, curriculum changes occur over time for a number of reasons and in January 2009 a core course in the Engineering and Society program was replaced. Historically, Society students took "Social Control of Technology" in their fifth and final year. The content of this course was integrated into a number of other core courses and in its place a society capstone design course was created and implemented in 2009, titled "Design for Society" (DFS). This core course was developed to enhance the value of education in the Society program and provide students with an opportunity to merge the fundamental knowledge they have accumulated in their core disciplines with the knowledge and values taken from their Society courses and focus electives. This course provides an opportunity to generate innovative solutions to a real-life, multi-dimensional problem involving a complex mix of ethics, culture, heritage, environmental, economic and engineering systems. The Society program has always been considered an innovative concept and in keeping with the times it was thought that the students should put to use the tools and ideologies they had been exposed to in a multi-disciplinary design environment. This is not a new concept and many academics and professionals have written on the need to incorporate multidisciplinary design in a social context within engineering [1] [4] [7].

It is readily apparent that our lifestyle choices have a substantial impact on energy and material resources as well as being a critical determinant of health, comfort, and productivity. In response, there are numerous local, provincial, national, and international entities adopting, what is often coined, "green" or "sustainable" criteria and indicators. Design which addresses a combination of social, environmental and economic needs should be sought by engineering professionals, though we know this is not always the case, especially when it comes to evaluating social consequences of design. Therefore, one aim of social design is to reach people who are currently not receiving the benefits of design. The purpose of introducing the capstone course was to provide a holistic understanding of the environmental, social and economic impacts of systems, processes and products.

The students obtained knowledge and experience with problem definition, brainstorming, sustainable design, innovation and critical thinking which will be essential for achieving more holistic and sustainable design solutions. The class was composed of 32 students from seven different departments in the Faculty of Engineering and the breakdown is shown in Table 1.

Table 1. Class composition

\begin{tabular}{|l|l|r|}
\hline Department & Students & Percentage \\
\hline Civil & 10 & 31 \\
\hline Materials & 8 & 25 \\
\hline Engineering Physics & 7 & 22 \\
\hline Software & 3 & 10 \\
\hline Mechanical & 2 & 6 \\
\hline Computer & 1 & 3 \\
\hline Chemical & 1 & 3 \\
\hline TOTAL & 32 & 100 \\
\hline
\end{tabular}

The students who participated in the capstone course were from seven diverse disciplines, and as such it was decided to provide them with a conceptual design problem which was broad in scope, dealt with societal/cultural issues and required them to showcase their creative abilities and engineering aptitudes. The design project, located in Canada's newest territory, Nunavut, is described in the following sections.

\subsection{Capstone Project}

Nunavut was separated officially from the Northwest Territories on April 1, 1999 making it the largest and newest territory of Canada. The capital is Iqaluit, located on Baffin Island and was formerly known as "Frobisher Bay". Other major communities include the regional centres of Rankin Inlet and Cambridge Bay. Nunavut has a population of only 29,474 spread over an area the size of Western Europe, making it the fifth-largest country subdivision in the world. Even 
though the territory is sparsely populated it is a culturally significant part of Canada with a rich history.

The students were told that the territorial government of Nunavut is interested in giving a boost to its tourist trade while showcasing the culture, history and heritage of their people. To this end they have invited tenders for an ecotourist proposal that will satisfy their needs. The objectives for the project are to develop an ecotourist destination in Iqaluit or the surrounding area that is aesthetically pleasing, functionally effective and efficient. The proposal could be for facilities or an event. The design was subject to the following constraints:

- Create a destination that will draw tourists to Nunavut.

- Showcase the history and culture of the people and area.

- If possible, make the "facility" adaptive and multi-use.

- Take into account local climate, conditions and building materials.

- Work within a $\$ 15$ million budget.

The students were asked to produce a final report which detailed their design process and showcased their chosen alternative. The design was to be conceptual in nature but with enough detail that the cost of the chosen solution could be roughly calculated.

\subsection{Contact Time}

The contact time for the course was three hours per week, with a one-hour meeting on Tuesdays and a two-hour meeting on Thursdays. In general the Tuesday class was an interactive discussion on different elements of the design process while the Thursday class was for group discussions, relevant videos, guest lecturers and time for the students to work on their projects. The topics that were covered in the lectures included: the design process, brainstorming techniques, critical thinking, creative problem solving, analysis tools, innovation, ethics and design, sustainability and design, design for environment, and industrial ecology. All of these topics were tuned to the final project and the students were expected to take many of the elements that were discussed and apply them to their conceptual design.

A former aboriginal resident of Iqaluit participated in the capstone course by providing a short presentation to the students concerning the living conditions and the culture of the Inuit people in Nunavut. The majority of the class was spent as a question and answer period. The students found this to be a very rewarding experience wherein many questions were answered that would have been difficult to research any other way. In addition, some groups asked for critical feedback from our guest speaker concerning their alternatives, which proved to be extremely helpful for them.

\subsection{Deliverables}

The students were expected to hit a number of milestones throughout the semester and submit elements of their final project at predetermined stages. The following key elements were submitted for grading:

- Group covenant

- Problem statement

- A list of brainstorming alternatives

- Methodology for assessing alternatives

- Selected alternative and progress report

- Economics analysis

- Preliminary drawings

The group covenant was a contract that the students drew up immediately after they formed their groups. They were given a template that described in general terms how they would act towards one another and then were asked to fill in specific penalty clauses that outlined how inappropriate behaviour would be dealt with. All groups had penalty clauses for covering situations that included missed meetings and deadlines or submittal of substandard material. The intent was to let the students self-monitor their groups and to eliminate the potential difficulties posed by one or more members shirking their duties.

There was a strong emphasis on the initial stages of the design process which included drafting a problem statement, brainstorming, generating alternatives, and finally the selection of the preferred alternative. In some courses it has been observed that students give these elements little thought and tend to skip as quickly as possible to the technical design stage before truly understanding the inherent complexities of a problem and the challenges of finding a balanced solution. It was hoped that by making the front-end of the design process more transparent (at least to the instructor), it would encourage students to think more about their choices and the potential impacts of their design solutions.

\subsection{Final Designs}

The final designs submitted by the students were diverse, ranging from structures such as ice hotels to events like a film festival. Table 2 lists the different projects presented by the groups. 
Most of the solutions in Table 2 should be selfexplanatory, and it is beyond the scope of this paper to describe any of the designs in detail. One term however, that may not be familiar is "voluntourism", which is part of the conceptual design for the eighth group. Voluntourism can be described as a volunteer vacation which involves participating in activities centered on aiding a community or furthering a charitable cause. The group designed a facility in Iqaluit to house the volunteers and also created the framework for the voluntourism program.

Table 2. Conceptual designs

\begin{tabular}{|l|l|}
\hline Group & Design \\
\hline 1 & Environmentally Friendly Cultural Centre \\
\hline 2 & Film Festival and Arctic Scuba Diving \\
\hline 3 & Arctic Academy of Travel and Tourism \\
\hline 4 & Adventure Hub Facility \\
\hline 5 & Ice Hotel \\
\hline 6 & Community Centre and Satellite Chalets \\
\hline 7 & Ecotourist Centre and Activities \\
\hline 8 & Voluntourism Centre \\
\hline
\end{tabular}

Many groups designed centralized facilities in and around Iqaluit that used up much of their budget. Others found that when they were analysing their alternatives using weighted matrices or an analytical hierarchy process that it was difficult to come up with a clear winner. Given the size of the budget that they were working with they felt that they could promote multiple alternatives and provide an "ecotourist package" that they felt satisfied the objectives that were set out in their problem statements. In all cases the students spent a large amount of time researching and developing the social side of their conceptual designs. Significant effort was put into justifying their ideas and how they would attract tourists to Nunavut without sacrificing the local culture or adversely impacting the environment.

\section{Reflections \\ 3.1 Positive Outcomes}

Overall the DFS capstone design course was a success. There were many aspects of the course that worked well and it can in part be attributed to the type of student that is attracted to this program. The Society program is well suited to individuals who have interests outside of engineering, enjoy lively debate, excel at inquiry-based learning and who have an interest in how technology impacts the world around them. These qualities contributed to the high level of commitment and enthusiasm that the students displayed. Even though the groups were self-selected there was a dedicated collaboration between the disciplines as they worked on a solution to the problem presented. Students with a background in Civil or Mechanical engineering had an advantage if their conceptual design involved designing a structure, such as a community centre. Other students wove their personal interests into their design such as the film festival or the voluntourism centre. In both cases one of the group members had a strong interest that helped shape their solution. In the case of the film festival, one of the students had completed a minor in drama through his focus electives in Engineering and Society. As for the group that created a voluntourism centre, a couple of members were extensively involved with Engineers Without Borders (EWB) and used their experiences to flesh out their design.

Another noteworthy element of the course was the brainstorming session. Each group submitted a list of alternatives that they generated that could possibly satisfy their problem statement. The diversity, creativity and innovation that the class displayed was remarkable. Many of the potential solutions were obviously not feasible (e.g. the polar bear rodeo) but that did not dissuade the groups from engaging in a free-flowing and productive exercise. Due to the nature of the problem and the short time period involved, the course focused heavily on the initial stages of the design process. The problem formulation, brainstorming and alternative evaluation stages were given a heavy weighting in the final report. The students had to come up with their own evaluation criteria in order to judge the merit of each of their alternatives. This forced the students to really study the impacts of their ideas and attempt to quantify the societal impacts of their different designs. It was not an easy exercise but it engaged the students and helped them explore the human side of engineering.

As with many group projects the marks were awarded based on participation, completion of required weekly components, a written report, and an oral presentation. For the oral presentation the class was told to assume that these presentations were being made to government representatives from Nunavut who would then pick one winning bid for their contract. Instead of a typical PowerPoint presentation the teams were encouraged to be creative and dynamic and to sell their concept to the best of their abilities. Many of the students took this to heart and produced lively and interesting presentations to showcase their designs in order to win the contract. The ability to communicate effectively is important as it is no longer enough to graduate students who are only proficient in their technical skills. They must be able to express their ideas, thoughts and concerns in a competent, logical and systematic way. Traditionally, there has 
been a disconnect in sharing information between engineers and the people who need them to solve their problems. Customers rarely know how to put their needs into technical words and some engineers are not necessarily proficient communicators and as such may, in turn, struggle to understand the needs of their clients. Engineers need to be comfortable with their communication skills in order to converse effectively with others. The capstone course, like most Engineering and Society courses, has many essential components built into it that will foster these softskills; skills that employers look for in new engineering graduates.

\subsection{Challenges Encountered}

There were a number of challenges encountered during the course including:

- Background knowledge

- Repeated material

- Scheduling

- Scope of the project

As mentioned the class was made up of students from seven different departments in the faculty of engineering. Each group had a diverse set of knowledge that they could build on. The challenge in this case however was the composition of each group. As the groups were self-selected some of the groups were not as diverse as others. The groups represented two or three departments, but none of the groups were comprised of four different departments. One could argue that this design project favoured Civil Engineers and there were a number of groups that did not have a representative from the Civil department. In addition one of the stipulations for the final design was that each team had to produce at least one CAD drawing. In some cases the students had not touched a CAD program since their first year at university and there were a couple of groups where none of the members were familiar with such a program.

Another challenge that was taken from the student feedback was that in some cases they had design courses in their home departments that covered some of the concepts that were discussed in the DFS course. In particular some students felt that classes concerning the design process, brainstorming and research overlapped material that they had taken in their home department. This however was not true for the entire class as it appears that some departments have a more formal design curriculum than others in the faculty.

Scheduling was very difficult for the students especially those groups with three departments represented. Scheduling Society classes in general is a challenge with so many different timetables that have to be accounted for. Some students reported that they had difficulty scheduling group meetings outside of class time. In addition some students had their own departmental capstone projects which required group meetings outside of class time as well.

The final challenge was the scope of the project. A few students were overwhelmed with the open-ended nature of the problem and had difficulty framing their problem statement. Many groups wanted more guidance and were worried that they would be penalized for a lack of creativity or in a few cases for pursuing a solution which might be considered by some as being too far outside of the box. In addition some individuals had difficulty applying the knowledge that they had accrued in their discipline to the design project. For instance the software engineers in the class relied more on their core Society courses than they did on their departmental program of study for their conceptual design. In the course evaluation forms a couple of students suggested that an improvement to the course would be to offer a number of different project topics.

\section{Future Directions}

There are a number of adjustments that will be made to the DFS course before its next offering. Some will be straightforward to implement and others will require more time and thought. The following list stems from personal observations as well as student feedback:

- Set groups

- More technical problems

- Multiple problems

- Less content

In order to ensure that the groups are well balanced and contain a highly diverse skill set, it was decided that the students won't be self-selecting their teams in the subsequent year. There is the danger that there will be more difficulties with group dynamics but the students need to understand that they don't necessarily get to pick their co-workers in the real world either. Hopefully the group covenant will help the teams manage themselves and take care of any personnel problems they encounter during the semester.

The design problem needs to be more technical and challenge the students to use not only their creative side but to mesh it with the fundamental engineering principals that they have learned over the years. The course focus is still to design with society in mind but it will require more calculation and theory than the initial offering did. In order to accommodate the various departments a number of different projects will be available for the students to choose from.

As many of the students have other courses that deal with engineering design in their home 
departments less class time needs to be spent on the common elements. Instead more time should be devoted to group exercises aimed at honing these skills and on design time with each group. One possible solution is to keep the course timetable as it is and make the two-hour meeting time a design studio. The instructor would meet with each group during the studio time and ask them about their project, probing their design and questioning choices or assumptions that they have made. This would help alleviate some of the difficulties that the students have in scheduling meetings outside of class time.

\section{Summary and Concluding Remarks}

The new capstone course, Design for Society, in the Engineering and Society program at McMaster was a success. The student feedback was quite positive and where there was criticism it was constructive. The students worked together in a multi-disciplinary environment and came up with some creative and innovative solutions to a very open-ended problem. There were a number of challenges that emerged as would be expected in a course in its first offering. The challenges however are not insurmountable and a capstone design course in the Engineering and Society program at McMaster University is exactly what the students need to be able to showcase their considerable talents and prepare them for an often multi-disciplinary working environment after graduation.

\section{References}

[1]Ashford N.A. (2004). Major Challenges to Engineering Education for Sustainable Development: What Has To Change to Make It Creative, Effective and Acceptable to the Established Disciplines. International Conference on Engineering Education in Sustainable Development. Berlin
[2]Goel Sanjay (2004), What is high about higher education: Examining Engineering Education Through Bloom's Taxonomy. The National Teaching \& Learning Forum, Vol. 13 Number 4, pp 1-5.

[3]Goel, Sanjay and Sharda, Nalin (2004). What Do Engineers Want?: Examining Engineering Education through Bloom's Taxonomy. Creating Flexible Learning Environments: Proceedings of the 15th Australasian Conference for the Australasian Association for Engineering Education and the 10th Australasian Women in Engineering Forum. Australasian Association for Engineering Education, 2004.

[4]Huntzinger, D.N., Hutchins, M.J., Gierke, J.S. and Sutherland J.W. (2007). Enabling Sustainable Thinking in Undergraduate Engineering Education. International Journal of Engineering Eudcation, 23 (2), 218-230.

[5]Lee, V.S. (2004). Promoting Learning through Inquiry. Essays on Teaching Excellence: Toward the Best in the Academy, Vol. 15, No. 3, 2003-2004. The Professional \& Organizational Development Network in Higher Education.

[6]Lockyer, John (editor) (1999). Evolution of Engineering Education in Canada: New Challenges for Canadian Universities. Engineering Issues No. 8, 1-2. Ottawa: Canadian Academy of Engineering.

[7]Rugarcia, A., Felder R, Woods D, Stice J (2000). The Future of Engineering Education I. Teaching Methods That Work. Chemical Engineering Education, 34(1), 16-25.

[8]Schank, Roger C. and Cleary, Chip (1995). Engines for Education. New Jersey: Lawrence Erlbaum Associates Incorporated. 